Dig Surg 1991;8:I-IV

\title{
Contents, Vol. 8, 1991
}

\section{No. 1}

Original Paper

Percutaneous Transhepatic Portal Catheterization as a Useful Diagnostic Method for

Localization of Insulinoma. Necessity of Precise Serial Blood Sampling Minote, H.; Inoue, K.;

Kogire, M.; Higashide, S.; Miyashi-ta, T.; Minematsu, S.; Imamura, M.; Uchida, K.; Tobe, T. 1

Relief of Inoperable Malignant Obstructive Jaundice following the Conversion of Percutaneous

Transhepatic Bile Drainage to Internal Drainage

İkei, S.; Yamaguchi, Y.; Katafuchi, S.; Mori, K.; Sera, Y.;

Ogawa, M 5

Patients with Heal Pouch-Anal Anastomosis Display Contrac

tile Abnormalities of the Reservoir and of the Upper Ileum

Bassotti, G.; Castagnoli, G.; Trancanelli, V.; Pelli, M.A.;

Morelli, A 10

Incidence of Colorectal Cancer following Polypectomy. A

Long-Term Follow-Up Study

Wille-Jørgensen, P.; Staune, L.; Dimo, B 15

Expression of c-myc Oncoprotein p62 in Normal Colon Mu-cosa and Colorectal Neoplasms: An

Immunohistochemical Study Suzuki, H.; Miura, T.; Matsumoto, K.; Ishijima, N. ... 19

Risk of Elective Surgery of Colorectal Carcinoma in the Elderly

Hesterberg, R.; Schmidt, W.U.; Ohmann, C; Röher, H.D.;

Sattler, J 22

Hemodynamic Changes in Progressively Lobectomized Liver of the Dog: Correlation with

Remnant Percentage of the Liver Sumi, S.; Inoue, K.; Doi, R.; Yun, M.; Kogire, M.; Tobe, T. 28

Surgical and Pseudosurgical Syndromes in Acquired Immunodeficiency Syndrome

Arsac, M.L.; Cugnenc, P.H.; Wind, P.; Lowenstein, W.; Tourani, J.M.; Francoual, G.N.; Faye,

A.; Siksik, J.M. . . 34

Case Reports

Radical Resection for Synchronous Primary Cancers of the Pancreas and Stomach

Dosei, T.; Miyata, M.; Yamaguchi, T.; Nakao, K.; Kawa-

shima, Y 39

Sonographic Diagnosis of Superior Mesenteric Artery Syndrome

Gavinelli, M.; Chisena, S.; Montagnolo, G; Anselmi, A.;

Andreoni, B 43

Multicentric Carcinoma in situ Occurring in a Villous Adenoma of the Appendix

Furutani, Y.; Nakao, K.; Hamaji, M.; Nakahara, M.; Shi-

mizu, S.; Tsujimoto, $\mathrm{M} \quad 48$

Duplication of the Cecum Mimicking an Obstructing Carcinoma in an Adult Woman Neeman,

A.; Feigenberg, Z.; Herskovitz, P.; Kadish, U. . 53 
Jejunal Infarction as a Complication of Postoperative Pancre atitis

Panichi, S.; Colugnat, D.; Fucini, C; Fargnioli, R 55

Minute Adenocarcinoma of Anal Duct Origin

Yamaguchi, A.; Ishida, T.; Nishimura, G; Kanno, M.;

Kosaka, T.; Yonemura, Y.; Miyazaki, 159

Sigmoidoappendiceal Fistula Secondary to Diverticulitis. Re port of a Case and Review of the Literature

Dearani, J.; Arcomano, T.; Bass, B.L 62

No. 2

Laparoscopic Cholecystectomy

Editorial $\quad 69$

Cholecystectomy - The 'Golden Standard' Treatment for Cholecystolithiasis: The Evolution of Surgical Technique

Jakimowicz, J.J

71

Minimal Access Surgery

Cuschieri, A 76

Laparoscopic Laser Cholecystectomy: Technique and Results

Reddick, E.J 79

Technical and Clinical Complications of Laparoscopic Chole cystectomy

Coburg, A.J.; Wolharn, R.; Weinelt, N 84

Gallstones: Laparoscopic Treatment - Cholecystectomy, Cholecystostomy and Lithotripsy

Perissat, J 86

Cholangiography and Choledochoscopy during Laparoscopic

Cholecystectomy, Its Place and Value

Berci, G 92

Laparoscopic Cholecystectomy - Personal Experience

Dubois, $\mathrm{F} \quad 97$

Borderline Indications for Laparoscopic Cholecystectomy

Wolharn, R.; Coburg, A.J.; Wienelt, N 101

Laparoscopic Cholecystectomy: Indications, Technique and

Results, Pros and Cons

Cuschieri, A 104

Laparoscopic Cholecystectomy in View of Medical Technology Assessment

Troidl, H.; Eypasch, E.; Al-Jaziri, A.; Spangenberger, W.;

Dietrich, A 108

IV

Contents

Ultrasound-Assisted Laparoscopic Cholecystectomy: Prelimi nary Experience

Jakimowicz, J.J.; Ruers, T.J.M 
Risks and Complications of Laparoscopic Cholecystectomy:

Critical Evaluation of the Method

Kempeneers, 1118

From the First Laparoscopic Cholecystectomy to the Frontiers

of Laparoscopic Surgery: The Future Prospectives

Mouret, P 124

Laparoscopic Cholecystectomy: A Multicenter Belgian Experi

ence

Gigot, J.F 126

Panel Discussion 128

Further Reading and References 133

Acknowledgement 136

No. 3

Review

Dumping Syndrome

Harju, E

137

Original Paper

Influence of Food, Posture and Gastric Alkaline Events on 24-

Hour Gastric and Duodenal $\mathrm{pH}$ in Normals

Brown, T.H.; Walton, G.S.; Manning, C; Thomas, H.A.;

Larson, G.M 149

Indication and Surgical Therapy in Uncomplicated Peptic

Ulcer Disease

Schafmayer, A.; Köhler, l·L; Neufang, T 157

Correlation of Computed Tomography Findings in Gastric Carcinoma with Surgical and

Pathological TNM Stage Sanchez Bueno, F.; Gomez Yelo, A.; Garcia Marcilla, J.A.; Felices

Abad, J.M.; Ramirez Romero, P.; Parrilla Paricio, P. 165

One-Year Survival after Surgical Treatment in UlCC-Classi-fied Pancreatic Cancer Patients

Heise, J.W.; Becker, H.; Borchard, F.; Krüger, M.; Röher,

H.-D 170

Prospective Randomized Study on the Necessity for Routine

Nasogastric Intubation after Major Abdominal Surgery

Clevers, G.J.; Hendriks, A.V.; Smout, A.J.P.M.; Akker-

mans, L.M.A.; van Vroonhoven, T.J.M.V 177

Puborectoplasty. New Technique for the Repair of Fecal In

continence

Shafik, A 182

Long-Term Results after Surgical Treatment of Organic Hyper-

insulinism

Böttger, T.; Junginger, T.; Beyer, J 187

No. 4

Original Paper

Cardiopexy with the Round (Teres) Ligament ('Sling Approach') in Surgery for

Gastroesophageal Reflux. Long-Term Results in 100 Cases Operated on 17-24 Years Before 
Narbona-Arnau, B.; Lloris-Carsí, J.M.; Calvo-Bermúdez,

M.A.; Zaragoza, C; Azcárraga, F 197

Detergent Properties Do Not Fully Explain the Barrier Disruption Induced by Bile Salts

Malthaner, R.A.; Dziki, A.J.; Harmon, J.W.; Fischer, B.A.;

Hakki, F.Z.; Bass, B.L.; Schweitzer, E.J 204

Correlation between Endoscopic and pH-Metric Findings and

Motor Oesophageal Alterations in Reflux Oesophagitis

Parrilla, P.; Martinez Haro, L.F.; Ortiz, M.A.; Ruiz, G.;

Aguayo, J.L.; Morales, G.; Garcia Marcilla, J.A 210

Jejunal Motility in Impaired Gastric Emptying

Pucciani, F.; Bini, S.; Bechi, P.; Cortesini, C 215

Is Preoperative Localization in Organic Hyperinsulinism Nec

essary or Not? A National Review

Böttger, Th.; Schäfer, W.; Beyer, J.; Junginger, Th 220

Surgical Aspect of Cancer of the Distal Pancreas. Comparison of Operative Findings, Mortality,

Morbidity, Physical Performance Status and Survival in Cancer of the Proximal and Distal

Pancreas

Miyata, M; Dousei, T.; Tanaka, Y.; Takao, T.; Kuwata, K.;

Nakao, K.; Kawashima, Y 225

Management of Bleeding Varices in Cirrhotic Patients Eligible for Liver Transplantation

Mentha, G.; Le Coultre, C; Meyer, P.; Huber, O.; Klopfen-

stein, C; Rohner, A 231

Case Reports

Anal Fistula - Fissure Complication

Deutsch, A.A.; Myers, E.; Stern, H 236

Invited Commentary

Winkler, R 238

Mucinous Cystadenoma and Cystadenocarcinoma of the Pancreas: Possibility for Late

Recurrence and Malignant Transformation

Sastre, B.; Carabalona, B.; Sahel, J.; Payan, M.J.; Agostini,

S.; Michotey, G 239

Adenosquamous Carcinoma of the Pancreas. Case Report and Clinical Review

Hirono, Y.; Nagakawa, T.; Ohta, T.; Takamura, H.; Naka-no, T.; Mori, K.; Kadoya,” N.;

Kayahara, M.; Ueno, K.; Miyazaki, I.; Nonomura, A.; Terada, T.; Matsui, O. ... 244

Case Reports

Actinomycosis: A Rare Cause of Perianal Disease

Gumbs, M.A.; Iyer, S.; Levy, J.L.; Carvajal, S.; Gerst, P.H. 192

Acute Chylous Peritonitis

Makena Marangu, J.A.; Gnassi, A.; Chung, H.R.; Spillert,

C.R.; Lazaro, E.J 194

Announcement 235

Erratum 243

Acknowledgement to the Reviewers

Author Index 249

Subject Index $\quad 251$ 